\title{
Development of a DSS and Online Tools to Support Sleep Disorder Consultations using Design Science.
}

\author{
Jacqueline Blake \\ School of Business \\ University of the Sunshine Coast \\ jblake@usc.edu.au \\ Don Kerr \\ School of Business \\ University of the Sunshine Coast \\ John Gammack \\ College of Technological Innovation \\ Zayed University
}

\section{Abstract}

Medical decision making takes placein a complex and dynamic environment, involving various individual and organisational stakeholders. In such contexts supportive information systems are required to be designed for practical efficacy, emphasising transparency, usability, and usefulness to their primary users. At the same time, they need to demonstrate improved efficiency and diagnostic accuracy. In addition, they also need to provide effective communication of relevant information. This paper describes the use of design science to develop and evaluate a DSS incorporated into online tools to support sleep physician's diagnosis of sleep disorders. The design science approach offers guidance for developing this solution, that ensure the artefacts fit into their usage context, and that development and evaluation principles that generalise to similar problem domains are identified. How this project fits in the design science guidelines is specified, thus demonstrating how this philosophy and methodology advances theory particularly relevant to other similar medical diagnostic domains. The usability and technical evaluation of the set of tools indicated provide clear practical benefits at patient, physician and organisational levels.

Keywords: Decision support system; sleep disorder; medical consultation; diagnosis; usability

\section{Introduction}

This paper describes designing an information system artefact in the environment of medical consultation. Medical consultation environments combine strict guidelines from biomedical theory and professional practice with discretionary elements sensitive to the individual's situation. There are various models for medical consultation which have chronologically evolved from "doctor as engineer" towards more patient-centric approaches (Pawlikowska et al. 2007), but generally embody essentially complex, two-way interactions involving history taking, problem solving and treatment or management decisions, with effective communication, information sharing and mutual understanding as central aspects.

Consultation for sleep disorders is representative of other specialised medical consultations in regard to the professional processes involved, and the requirement to communicate and understand relevant information. This paper uses the case of sleep consultation to describe the development of relevant support for this process. Sleep disorders are still under-observed by primary physicians (Bailes et al. 2008) and despite increased awareness of sleep disorders among physicians and the wider community there is a shortage of sleep disorder specialists in Australia (Australian Medical Workforce Advisory Committee 2000, Hillman \& Lack 2013), but also in the USA (Rogers \& Valerio 2011) and elsewhere, producing increasing burden on national health care systems (Cooper, 2013), Sleep disorders cost Australia 5.1bn per year, and considerably more if productivity losses due to poor sleep habits are included (Hillman \&Lack 
2013). The sleep community is therefore interested in changing the traditional model of care for sleep disorders to one that leverages information systems to provide efficiencies and timely communication flows (Colten \&Alterogt 2006).

Health informatics is defined as "a combination of computer science, information science and health science designed to assist in the management and processing of data, information and knowledge to support healthcare and healthcare delivery (Conrick 2006, p. 4). Health informatics now forms part of the infrastructure for the delivery of healthcare with one of the major fields of research being decision support (Haux 2010). Health informatics allows the timely retrieval and filtering of patient and disorder information so that caregivers have appropriate information in a quickly assimilated format within their workflow. Hirakis \& Karakounos (2006) and Haux (2010) state that knowledge management in healthcare allows the development of best practice models, making guidelines explicit and encourages innovation through development of the resultant knowledge base. This allows clinicians access to updated knowledge, but also helps skilled caregivers, or the patients themselves, to understand the rationale to manage treatments. For effective knowledge management, information shared should, ideally, be captured in the flow of work practice, so that it does not impose an overhead on rekeying, communication and storage. In addition, for effective knowledge sharing, an agreed vocabulary is essential to avoid misunderstanding, and collaborative ontologies with controlled vocabularies are becoming established in the biomedical sector (Simperl \& Luczak-Rosch 2014).

Our research develops information tools to support both the patient and physician in the diagnosis of sleep disorders. Following the Design Science Research (DSR) approach, the artefact described in this paper aimed to improve communication and workflow, by redesigning a complex manual process that previously relied upon input from sleep physicians and sleep clinic staff to process data (Hevner et. Al 2004). The rest of the paper proceeds as follows, we first briefly review background literature to demonstrate the need for such tools, particularly in the area of sleep consultation and outline the case context and its requirements. We then review the DSR methodology and in detail demonstrate its application to develop and evaluate an IT artefact for the illustrative case. In section 4 we discuss the findings and make clear the knowledge contribution. Finally, we draw conclusions, discuss limitations and generalisation, and avenues for further research.

Approximately six per cent of the Australian population have a sleep disorder but only 20 per cent of those affected by sleep disorders are diagnosed (Access Economics Pty Limited 2004), other countries report similar statistics (Young, Peppard \&Gottlieb 2002) with the people who are referred for treatment being strongly symptomatic (Kramer et al. 1999). In recent times within Australia there is an average wait for an initial consultation with a sleep physician of nine weeks with a further average wait of 21 weeks for a sleep study to diagnose a sleep disorder (Flemons et al. 2004). While the average wait time for an initial consultation is six months in the United Kingdom, Belgium one to three weeks and United States of America two to twelve weeks. These wait times demonstrate a gap between demand for sleep disorder assistance and the ability of the most health services to provide for the current level of people referred to sleep clinics.

This research project looked at the development of a system to support the diagnosis of sleep disorders. The requirements were unclear and the subject matter experts who were sleep specialists had limited time to provide guidance and feedback, so there was a need for a rigorous framework to ensure the developed artefact was of an acceptable quality as well as producing an application which would work in the environment and be useful and usable. The online sleep tools which incorporated a decision support system were developed to improve communication flows between the physician and patient. A qualitative approach was used, acknowledging the complex and dynamic medical socio-technical environment. The requirements for the online applications were captured using convergent interviews with physicians and allied health professionals who were working in the sleep disorder environment. Observations were also made of sleep physicians during patient- physician consultations (with the patient's permission). Through a process of iterative development, 
prototypes of each application were built, using the feedback from health professionals. The extant literature was used to focus on the current sleep disorder context, and the theory drawn from this literature applied in a cyclical way to the sleep disorder clinic under study.

Design science research provided a framework which met these requirements. As stated by Arnott and Pervan (2014) design science research has becomea popular method for developing decision support systems, this paper provides a case study of a design science project which resulted in the output of an IT artefact which was evaluated as usable and useful by users.

\section{Design Science}

Design science is a problem solving approach aimed at changing an existing environment to one which better reflects current aims (Boland 2002). Walls, Widmeyer and El Sawy (2004, p. 45) describe the purpose of design theory as being "to guide artefact creation". Specifically, in information systems, design science creates and evaluates information technology artefacts designed as a solution to a problem (Hevner et al. 2004).

Walls, Widmeyer and El Sawy (1992) differentiate design theory from natural and social science research by stating that in design theory research "the achievement of goals" is fundamental (Walls, Widmeyer \& Sawy 1992, p. 40). This contrasts with natural and social science theory which seeks to explain or predict phenomena. They further state that design theory puts explanatory, predictive and normative theory into practical use by designing an artefact to meet a goal. This may seem to contradict the critical realist stance adopted in this project; however, Carlsson (2006) argues that critical realism is an appropriate stance for design science research because, although the goal is to produce an IT artefact which will work for a class of problems, that IT artefact must be evaluated within the socio-technical environment that forms its context. This context and social science theory guide the process of forming the requirements for an IT artefact.

The goal of a design science research project is the successful application of the designed object to make required changes in an environment. Walls, Widmeyer and El Sawy (1992) based their paper upon Simon's (1969) book which argued the need for a formal methodology to govern design, and applied this approach to the information systems field. Walls, Widmeyer and El Sawy (1992) start a formal definition of design theory by stating that "design is both a product and a process" (Walls, Widmeyer \& Sawy 1992, p. 42) and consequently, that the use of design theory methodologies is as important as the evaluation of the designed artefact itself. They state that the process of producing the artefact requires three elements:

- A design method that describes how the artefact was constructed

- A kernel theory from the natural or social sciences so that the design process is driven by extant process theory

- A testable design process hypothesis, to evaluate whether the designed artefact meets the standards of its design class.

Further, the designed product must meet four requirements:

- Meta-requirements, which provide an understanding of the system requirements that are necessary in a solution to the identified problem

- Meta-design, which is knowledge of the types of artefacts shown to provide a solution in this problem domain

- A kernel theory, as the artefact must be informed by the extant theory

- A testable design product hypothesis, which is a plan for evaluating whether the designed artefact meets the requirements. 
The Walls, Widmeyer and El Sawy (1992) diagram of the relationship between these requirements is shown in Figure 1. This diagram was unchanged in a later paper critiquing the 1992 paper (Walls, Widmeyer \& Sawy 2004).

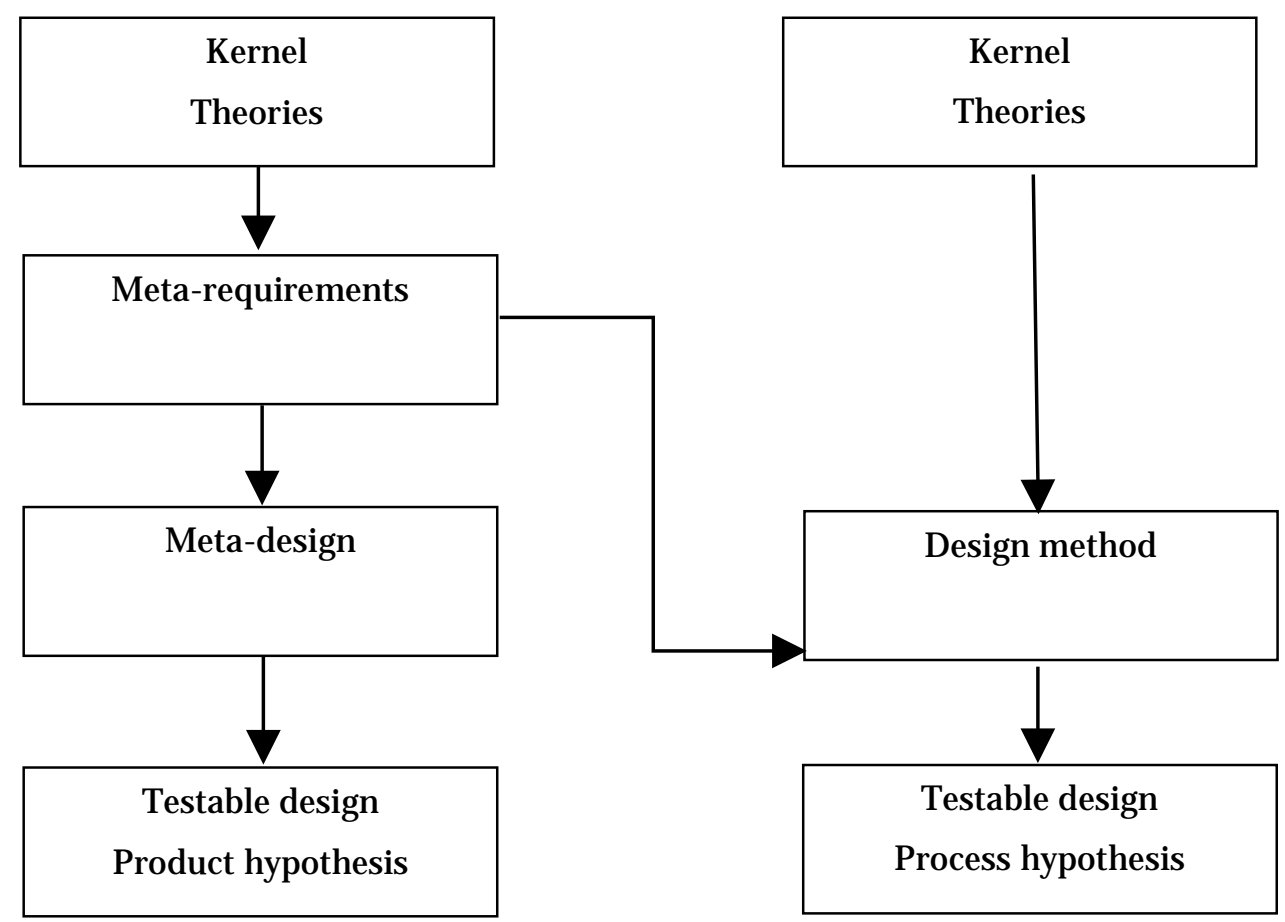

Figure 1 Components of an Information System Design Theory. (Source: Walls, Widmeyer \&El Sawy, 1992).

Markus, Majchrzak and Gasser (2002, p. 180) state that the contribution of Walls et al. (1992) serves to "articulate the boundaries within which particular design assumptions apply". This means that the contribution was for a rigorous research method based upon theory for a class of problem when the projects resulted in an artefact designed to introduce change in an environment.

March and Smith (1995) also draw upon Simon's (1969) work in discussing design science but do not reference Walls, Widmeyer and El Sawy (1992). They state that "rather than producing general theoretical knowledge, design scientists produce and apply knowledge of tasks or situations in order to create effective artifacts." (March \& Smith 1995, p. 253). This implies that the focus of the process is on designing relevant practical artifacts "that serve human purposes" (March \& Smith 1995, p. 253) at the expense of building design theory.

Later authors have agreed with Walls, Widmeyer and El Sawy (2004). These include Gregor and J ones (2007), Kuechler and Vaishnavi (2008), Hevner et al. (2004) and Venable (2006). However, Baskerville (2008, p. 442) refers to the theory produced by design science as "theory discovery" where the theory is a by-product of the process of constructing an environmentchanging artefact. Further, Winter (2008, p. 472) refers to theory as an "intermediate artefact" that needs to be included in the list of artefacts which result from design research. He also states that to be classed as design research, the process and product of the research must retain some generalisibility to that class of problem domains. This is related to the Walls, Widmeyer and El Sawy (1992) meta-requirements and meta-design in their formal definition of design theory.

\section{Methodology}

The design science approach used in this project was that proposed by Hevner et al. (2004), using the Klein and Myers (1999) method. This approach has been acknowledged by Venable 
(2006) as being accepted by the information systems community, although it lacks a clear statement about the role of theory. The Hevner et al. (2004) guidelines in Table 1 outline a framework for performing design science research. These requirements differentiate a research approach to developing an information technology artefact from an approach taken in routine system development.

\begin{tabular}{|l|l|}
\hline Guidelines & Description \\
\hline $\begin{array}{l}\text { 1: Design as an } \\
\text { artefact }\end{array}$ & $\begin{array}{l}\text { Science research must produce a viable artefact in the form of a } \\
\text { construct, a model, a method or an instantiation. }\end{array}$ \\
\hline 2: Problem relevance & $\begin{array}{l}\text { The objective of design-science research is to develop } \\
\text { technology-based solutions to important and relevant business } \\
\text { problems. }\end{array}$ \\
\hline 3: Design evaluation & $\begin{array}{l}\text { The utility, quality and efficacy of a design artefact must be } \\
\text { rigorously demonstrated via well-executed evaluation methods. }\end{array}$ \\
\hline $\begin{array}{l}\text { 4: Research } \\
\text { contributions }\end{array}$ & $\begin{array}{l}\text { Effective design-science research must provide clear and } \\
\text { verifiable contributions in the areas of the design artefact, } \\
\text { design foundations, and/ or design methodologies. }\end{array}$ \\
\hline 5: Research rigor & $\begin{array}{l}\text { Design-science research relies upon the application of rigorous } \\
\text { methods in both the construction and evaluation of the design } \\
\text { artefact. }\end{array}$ \\
\hline $\begin{array}{l}\text { 6: Design as a search } \\
\text { process }\end{array}$ & $\begin{array}{l}\text { The search for an effective artefact requires utilizing available } \\
\text { means to reach desired ends while satisfying laws in the } \\
\text { problem environment. }\end{array}$ \\
\hline $\begin{array}{l}\text { 7: Communication of } \\
\text { research }\end{array}$ & $\begin{array}{l}\text { Design-science research must be presented effectively to both } \\
\text { technology-oriented and management-oriented audiences. }\end{array}$ \\
\hline
\end{tabular}

Table 1: Design science research guidelines, drawn from Hevner, March, Park and Ram (2004).

The guidelines shown in Table 1 relate to this project as follows.

\subsection{Design as an artefact}

An information technology artefact consisting of a decision support system and input applications to support the diagnosis of sleep disorders was planned in this project. A definition of an information technology artefact is "the configuration of hardware and software, including user interfaces and algorithms intended to accomplish specific information processing of functions" (Chiasson et al. 2007, p. S90). According to Orlikowski and Lacono (2001), information technology artefacts had historically not been a focus as part of information technology research, but had been treated as static objects. Orlikowski and Lacono (2001) surveyed the extant literature and found that there were five main categories of how the information technology artefacts had been perceived. They identified a "Tool view", which comprised four elements: a Labour substitution tool, a Productivity tool, an Information processing tool and a Social relations tool. The Tool view sees an artefact as a static "thing" which carries out a required activity independently of its context. The artefact is considered to be a constant in the research with that which is "affected, altered or transformed" by the tool being the variable of interest (Orlikowski \& Lacono 2001, p. 123).

The four tools are described below.

- Labour substitution tool were the artefact is viewed as something that will replace human labour, allowing downsizing of the labour force to take place.

- Productivity tool were the artefact replaces older methods for carrying out work, thus increasing worker productivity by enabling flexible, collaborative work methods. 
- Information processing tool: This is the view that technology is capable of altering and improving the way that workers process information, thus enabling it to better flow through an organisation.

- Social relations tool where technology acts to alter the way and mode of communicating within both an organisation and a social network.

In the sleep study project, the development of an information technology artefact within the context of a public health clinic was viewed as both an information processing tool and a social relations tool. The evaluation of the online tools demonstrated that the tools provided a viable solution to the sleep disorder consultation domain.

\subsection{Problem relevance}

The use of decision support systems for providing evidence-based medicine has been described as one of the most important current and future research areas in health informatics (Haux 2010). Decision support systems have already been used successfully for diagnostic support (Lin, Hu \& Sheng 2006) with physicians shown to value decision support (Dreiseitl \& Binder 2005). The relevance of this problem is that sleep disorders, as discussed in previous section are becoming an increasing burden to the health system. Therefore, decreasing the health burden by increasing the quality of communication between a physician and patient, increasing a patient's self-knowledge and increasing the rigour of the diagnostic process provides a key, in part, to this important problem. Therefore, the problem addressed by this research provides a technology based solution to an important organisational problem within the sleep clinic and provides benefits to the wider community.

\subsection{Design evaluation}

In line with design science requirements, standard, well documented methods based on the extant literature have been used in the evaluation of the information system artefacts in this project. The sleep tool web application is intended to be used first, by patients with potentially limited computer literacy, and then by physicians who will use the application for diagnostic purposes. It was therefore essential to ensure that the application was usable. The International Standards Organisation (ISO) defines usability in standard 9241- 11 as "extent to which a product can be used by specified users to achieve specified goals effectively, efficiently and with satisfaction in a specified context of use" (Zikmund 2003). This evaluation investigates whether both patients and physicians could use and understand the application to an acceptable standard.

Three types of users - End users, two sleep physicians and a software engineer - helped to assess the various tools produced in this research. All three types of users had the software tools demonstrated and used the tools to assess usability.

The software engineer was given access to the sleep tool web application and was asked to provide his comments on the usability of the application as he completed all sections. The research objectives of this evaluation were for a professional software engineer to comment on the technical usability and design aspects of the sleep tools web application. The objective of the physicians' investigation was to ensure that the sleep tool web application had value in diagnosing sleep disorders, and met the sleep physicians' needs that they had detailed during the phase of requirements discovery. The objectives of the end user evaluation were to ensure that the sleep tools web application was robust and that it was reliable and usable (Blake, Kerr \&Gammack 2016).

Hence the evaluation of the IT artefact for utility, quality and efficacy was undertaken and satisfactory results produced using the application of usual usability testing methods.

\subsection{Research Contribution}

The information technology artefact developed in this project provides clear and verifiable contributions to the support of consistent clinical diagnosis of sleep disorders. Another 
contribution is the demonstration of improvements in the operational performance of the sleep clinic by the application of a set of online tools to the consultation interaction.

The output from the sleep tools web application allows an efficient, consistent triage process before a physician sees a patient for the first time. The operational implication of this is that a patient with a high risk of sleep apnoea can be sent to have a polysomnography before a consultation with a sleep physician. This acts to shorten the diagnostic interaction by at least one consultation, thus freeing the physician to see more new patients and reducing the cost of treating each of these patients.

Another operational benefit of removing patient history taking from the consultation is the possibility of the physician being able to shorten the duration of the consultation. This means that the physician is then free to carry out other tasks or to see more patients in the same length of time. As a shortage of physicians trained in the sleep speciality already exists and, as Dement (2008) suggests an aging population will exacerbate that shortage, then finding time gains and efficiencies during the consultation is important for patient wait times and the cost of treating the disorder.

The sleep tools web application automatically saves the patient history and sleep diary data in a database. This database of aggregated patient history data may then form a valuable resource for researchers, as it will have the facility to export unidentified data in an eXtensible Markup Language (XML) format. This aggregated information is not currently available within this health service as hard-copy patient records are still used.

\subsection{Research Rigor}

The framework for research quality proposed by Healy and Perry (2000) was used to ensure research rigor and quality in line with the design science approach. This framework was chosen because the critical realism qualitative approach used in the sleep study fitted the requirements of this framework. There are six quality criteria in this framework are detailed in the table below:

\begin{tabular}{|l|l|}
\hline Criterion & Project \\
\hline Analytic & $\begin{array}{l}\text { The project looked at a socio-technical environment, with a complex } \\
\text { interaction of people and technology. Therefore, this project was } \\
\text { appropriately world three with abstract things that exist separate from } \\
\text { people (Healy \& Perry 2000, p. 120) }\end{array}$ \\
\hline Contingent validity & $\begin{array}{l}\text { The resultant applications from the research were tested within the } \\
\text { context of the research. }\end{array}$ \\
\hline $\begin{array}{l}\text { Multiple perceptions } \\
\text { involving } \\
\text { triangulation }\end{array}$ & $\begin{array}{l}\text { More than one physician and SIU were included in the research. More } \\
\text { than one method of data collection was used with an interviewee given } \\
\text { the opportunity to correct notes after interpretation by the researcher. }\end{array}$ \\
\hline $\begin{array}{l}\text { Methodological } \\
\text { trustworthiness }\end{array}$ & $\begin{array}{l}\text { A rigorous method of data collection was used with a documented chain } \\
\text { of evidence, so that quotations could be used. }\end{array}$ \\
\hline $\begin{array}{l}\text { Analytic } \\
\text { generalisation }\end{array}$ & $\begin{array}{l}\text { This project will add to work on the use of online tools in an eHealth } \\
\text { environment. }\end{array}$ \\
\hline Construct validity & $\begin{array}{l}\text { The construct validity of the project was tested by conducting pilot } \\
\text { projects to test the validity of the tools. The maintenance of a chain of } \\
\text { evidence and triangulation also aided compliance with this criterion. }\end{array}$ \\
\hline
\end{tabular}

Table 2: Research quality criteria (adapted from Healy \& Perry 2000).

\subsection{Design as a search process:}

A mixed method approach was used in this project, acknowledging the complex and dynamic medical socio-technical environment. The foundations of the sleep disorder process and 
requirements for the web applications were uncovered using a search process based upon qualitative methods and the existing literature. Methods used were convergent interviews with physicians and allied health professionals who were working in the sleep disorder environment. Observations were also made of sleep physicians during patient- physician consultations (with the patient's permission). Through a process of iterative development, prototypes of each application were built, using the feedback from health professionals. The extant literature was used to focus on the current sleep disorder context, and the theory drawn from this literature applied in a cyclical way to the sleep disorder clinic under study.

This frame of reference made the project suitable for a design science project using a hermeneutic approach, with the outputs from the interviews and observations forming the text under study. The Klein and Myers' (1999) hermeneutic framework was used to inform the Hevner et al. (2004) design science research guidelines for the development of an IT artefact which changes an environment to better reflect current aims (Boland 2002). These guidelines were followed in the production of the IT artefact that resulted from this project.

Klein and Myers (1999) see the hermeneutic circle as the fundamental or meta-principle of hermeneutics. The hermeneutic circle is the action of studying components of the system for understanding, and looking at their interactions with the system as a whole (Klein \& Myers 1999, Trauth \& J essup 2000). For example, in this study the context of sleep medicine was researched, followed by a search for the requirements for an online sleep diagnosis tool. Following the development of the sleep tool web application, the context of the Prince Charles sleep investigation unit was reviewed to see how the introduction of this tool affected the relationships between users and technology. It is during this period of critical reflection on the problem domain that the research processes are formalised; at this point a deliberate quest for understanding takes place: the results from the cycle are written up and critiqued, and the tacit knowledge gained from this part of the study is made explicit (Dick 1998). Klein and Myers (1999) describe this undertaking as "extending in concentric circles the unity of the understood meaning". The hermeneutic cycle was also employed as part of this study by proceeding from the segment currently under study to the extant literature in the current problem domain.

\subsection{Communication of Research}

The results of this research have been promulgated to the information systems community by publishing in journals (Blake \& Kerr 2010, 2014; Blake, Kerr \& Gammack 2016). Communication of the research within the sleep community has been undertaken at conferences (Blake \& Kerr 2007) and in person at the sleep clinics under study.

\section{Discussion}

Design science provided the foundation for the successful completion of this project by ensuring that the research activities and processes were based on a design method, kernel theory and testable design process hypothesis.

One of the physician concerns was that the diagnosis and treatment of sleep disorder patients needed to be consistent across the sleep investigation unit. The reports from the sleep tools web application provide a logical protocol for providing a diagnosis that is based on industry standard criteria, the International Classification of Sleep Disorders (American Academy of Sleep Medicine 2005). The objective at the start of the research project was to provide the sleep physicians with a time-efficient, consistent diagnostic protocol. This project has endeavoured to do this by removing most of the responsibility for completing standard information gathering questionnaires from the sleep physicians to the patient. The sleep physician has access to reports which summarise and present the information from the online patient applications. The sleep diary report does this by applying programming logic to the patient's data, by presenting the sleep physician with a graphical representation of the sleep patterns, and by calculating the required sleep statistics from the patient's data. This enables the 
physician to access the sleep diary information without spending time making manual calculations.

The output from the patient history questionnaire is funnelled through a decision support system. The patient history data is separated into sections with the patient demographic and familial information presented in a clear, easy-to-understand format for the physician. Data that is specific to the sleep disorder is separated into disorder-specific then disorder-criteriaexplicit sectors, then processed through a series of small argument trees. This follows the literature specifically that of Stranieri et al. (1999), who used this method for discretionary decision making in the judicial system based on the theory contained in Toulmin (1958) book on the uses of argument. This method has worked in the sleep tools web application, with the argument trees presenting a clear explanation on the physician's report about why a patient has met a criterion for a sleep disorder.

\section{Conclusions}

By having patients record their details before their initial consultation, the online tools assist the sleep physician to keep the consultation patient-driven rather than form-driven. This means that the patient arrives at the consultation more prepared, the online tools having helping to demonstrate some of the factors that impact on sleep. Additionally, the sleep physician has more time during the consultation to move beyond making a diagnosis and into a personalised discussion about the treatment plan.

Therefore, the online tools developed using the design science framework help to support the physicians' diagnosis by providing reports that present patient information in a quickly assimilated format, give an objective second opinion of a diagnosis, provide a standard protocol for making the diagnosis based on international sleep disorder classifications and improve patient and physician communication during a consultation. While this project was situated in and produced a product for the particular situation of a sleep clinic, the success of this artefact was predicated on an understanding of the requirements of a health environment, a knowledge of the types of artefacts shown to provide a solution and an extent theory proven to work in other domains. These features fit the requirements for design science. Therefore, the design science framework shaped an IT artefact that met the physicians concerns and needs.

\section{References}

Access Economics Pty Limited 2004, "Wake up Australia: The value of healthy sleep", Available at: https://www.sleep.org.au/documents/item/69 [Accessed 17 J anuary 2007]

American Academy of Sleep Medicine 2005, "International classification of sleep disorders 2nd ed", Westchester, Illinois: Diagnostic and Coding Manual.

Arnott, D \& Pervan, GP 2014, "A Critical Analysis of Decision Support Systems Research Revisited: The Rise of Design Science", J ournal of Information Technology, vol. 29, no. 4, pp. 269-93.

Australian Medical Workforce Advisory, C 2000, "The specialist thoracic medicine workforce in Australia; supply and requirements 1999-2010", Australian Medical Workforce Advisory Committee, AMWAC, North Sydney.

Bailes, S, Baltzan, M, Rizzo, D, Fichten, CS, Amsel, R \& Libman, E 2008, “A diagnostic symptom profile for sleep disorder in primary care patients", J ournal of Psychosomatic Research, vol. 64, no. 4, pp. 427-33, ScienceDirect.

Baskerville, R 2008, “What design science is not”, European J ournal of Information Systems: Special Issue on Design Science Research, vol. 17, no. 5, pp. 441-3, Proquest. 
Blake, J \& Kerr, D 2007, “Implementing an online sleep diary to better manage sleep disorder diagnosis", in World Sleep 07: proceedings of the World Sleep 07 Cairns, Australia September 2-6.

Blake, J \& Kerr, D 2010, “Development of an online sleep diary for physician and patient use”, Knowledge Management \& E-Learning: An International J ournal, Special Issue on EHealth: Accessing Knowledge for Global Health, vol. 2, no. 2.

Blake, J \& Kerr, D 2014, "Sleep disorder diagnosis: an analytical approach", Decision Analytics, vol. 1, no. 7.

Blake, J N, Kerr, DV \& Gammack, JG 2016, "Streamlining patient consultations for sleep disorders with a knowledge-based CDSS", Information Systems, vol. 56, pp. 109-19.

Boland, RJ 2002, "Design in the punctuation of management action, Managing as design: Creating a vocabulary for management education and research", Available at: http:// design.case.edu/2002workshop/ positions.html. [Accessed 07 December 2009].

Carlsson, SA 2006, 'Design science research in information systems: A critical realist perspective', in 17th Australasian Conference on Information Systems Design Science Research in IS: proceedings of the17th Australasian Conference on Information Systems Design Science Research in IS Adelaide.

Chiasson, M, Reddyb, M, Kaplanc, B \& Davidson, E 2007, 'Expanding multi-disciplinary approaches to healthcare information technologies: What does information systems offer medical informatics?', International J ournal of Medical Informatics, vol. 76, no. Supplement 1, pp. S89-S97.

Colten, HR \& Alterogt, MM 2006, Sleep disorders and sleep deprivation: An unmet public health problem, National Academies Press, Available at: http:// books.nap.edu/ catalog.php?record_id=11617\#toc. [Accessed 29 December 2008].

Conrick, M 2006, Health informatics: Transforming healthcare with technology, Thomson Social Science Press, Melbourne.

Dement, WC 2008, 'History of sleep medicine', Sleep Medicine Clinics, vol. 3, no. 2, pp. 147256.

Dick, B 1998, "Cyclic critical reflection", Available at: http:// www.scu.edu.au/ schools/ gcm/ ar/ arm/ op009.html [Accessed 30 October 2015]

Deiseitl, S \& Binder, M 2005, "Do physicians value decision support? A look at the effect of decision support systems on physician opinion", Artificial intelligence in medicine, vol. 33, no. 1, pp. 25-30.

Flemons, WW, Douglas, NJ, Kuna, ST, Rodenstein, DO \& Wheatley, J 2004, "Access to diagnosis and treatment of patients with suspected sleep apnea", American J ournal of Respiratory and Critical Care Medicine, vol. 169, pp. 668-72.

Gregor, S \& J ones, D 2007, "The anatomy of a design theory", J ournal of the Association for Information Systems, vol. 8, no. 5, pp. 313-35, viewed 09 J une 2010.

Haux, R 2010, “Medical informatics: Past, present, future”, International J ournal of Medical Informatics, vol. 79, no. 9.

Healy, M \& Perry, C 2000, "Comprehensive criteria to judge validity and reliability of qualitative research within the realism paradigm", Qualitative Market Research: An International J ournal, vol. 3, no. 3, pp. 118-26.

Hevner, AR, March, ST, Park, J \& Ram, S 2004, "Design science in information systems research", MIS Quarterly, vol. 28, no. 1, pp. 75-105. 
Hillman, DR \& Lack, LC 2013, "Public health implications of sleep loss: the community burden”, The Medical J ournal of Australia, vol. 199, no. 8, pp. 57-60.

Hillman, DR, Murphy, AS \& Pezzullo, L 2006, "The economic cost of sleep disorders", Sleep, vol. 29, no. 3, pp. 299-305.

Hirakis, O \& Karakounos, S 2006, "Goals and benefits of knowledge management in healthcare", in AA Lazakidou (ed.), Handbook of Research on Informatics in Healthcare and Biomedicine, Idea Group Reference, pp. 193-200.

Klein, HK \& Myers, MD 1999, “A set of principles for conducting and evaluating interpretive field studies in information systems", MIS Quarterly, vol. 23, no. 1, pp. 67-93.

Kramer, NR, Cook, TE, Carlisle, CC, Corwin, RW \&Millman, RP 1999, “The role of the primary care physician in recognizing obstructive sleep apnea", Archives of Internal Medicine, vol. 159, no. 9, pp. 965-8.

Kuechler, B \&Vaishnavi, V 2008, "On theory development in design science research: anatomy of a research project", European J ournal of Information Systems: Special Issue on Design Science Research, vol. 17, no. 5, pp. 489-504, viewed 01J une 2010.

Lin, L, Hu, PJ-H \& Sheng, ORL 2006, “A decision support system for lower back pain diagnosis: uncertainty management and clinical evaluations", Decision Support Systems, vol. 42, no. 2, pp. 1152-69.

March, ST \& Smith, GF 1995, "Design and natural science research on information technology", Decision Support Systems, vol. 15, no. 4, pp. 251-66.

Markus, ML, Majchrzak, A \& Gasser, L 2002, "A design theory for systems that support emergent knowledge processes”, MIS Quarterly, vol. 26, no. 3, pp. 179-212.

Orlikowski, W \& Lacono, SC 2001, "Research commentary: Desperately seeking the 'IT' in IT research--A call to theorizing the IT artefact", Information Systems Research, vol. 12, no. J une, pp. 121-34.

Patlak, M 2005, "Tips to help you detect common sleep disorders", American College of Physicians, Available at, http://www.acponline.org/clinical_information/journals_publications/acp_internist/ mar05/ sleep.htm\#pool_[Accessed 20 J une 2016]

Pawlikowska, T, Leach, J , Lavallee, P, Charlton, R \& Piercy, J 2007, “Consultation models”, in R Charlton (ed.), Learning to consult, Oxford, Radcliffe

Rogers, AE \&Valerio, TD 2011, “The Role of Advanced Practice Nurses (APRNs) in Specialized Sleep Practice", in NS Redeker \& GP McEnany (eds), Sleep Disorders and Sleep Promotion in Nursing Practice, Pringer Publishing Company LLC, NewYork, pp. 371-8.

Simon, HA 1969, "The sciences of the artificial”, M.I.T. Press, Cambridge, Massachusetts.

Simperl, E \& Luczak-Rosch, M 2014, "Collaborative ontology engineering: a survey", The Knowledge Engineering Review, vol. 29, no. 1, pp. 101-31.

Stranieri, A, Zeleznikow, J , Gawler, M \&Lewis, B 1999, “A hybrid rule- neural approach for the automation of legal reasoning in the discretionary domain of family law in Australia", Artificial Intelligence and Law, vol. 7, no. 2-3, pp. 153-83.

Toulmin, SE 1958, "The uses of argument”, Cambridge University Press.

Trauth, EM \& J essup, LM 2000, “Understanding computer-mediated discussions: Positivist and interpretive analyses of group support system use”, MIS Quarterly, vol. 24, no. 1, pp. 43-79.

Venable, JR 2006, "The role of theory and theorising in design science research", in First International Conference on Design Science Research in Information Systems and Technology: proceedings of the First International Conference on Design Science 
Research in Information Systems and Technology, A Hevner \& S Chatterjee (eds.), Claremont, California, pp. 1-18.

Walls, J , Widmeyer, G \& Sawy, E 1992, “Building an information system design theory for vigilant EIS", Information Systems Research, vol. 3, no. 1, pp. 36-59.

Walls, J, Widmeyer, G \& Sawy, E 2004, "Assessing information system design theory in perspective: How useful was our 1992 initial rendition", Journal of Information Technology Theory and Application, vol. 6, no. 2, pp. 43-58.

Winter, R 2008, "Design science research in Europe”, European Journal of Information Systems vol. 17, no. 5, pp. 470-5.

Young, T, Peppard, PE \& Gottlieb, DJ 2002, “Epidemiology of Obstructive Sleep Apnea: A population health perspective", American J ournal Respiratory Critical Care Medicine, vol. 165, no. 9, pp. 1217-39.

Zikmund, WG 2003, 7th edn, "Business Research Methods", Thomson South-Western, Mason United States of America.

Copyright: (C) 2016 Blake, Kerr \& Gammack. This is an open-access article distributed under the terms of the Creative Commons Attribution-NonCommercial 3.0 Australia License, which permits non-commercial use, distribution, and reproduction in any medium, provided the original author and AJ IS are credited.

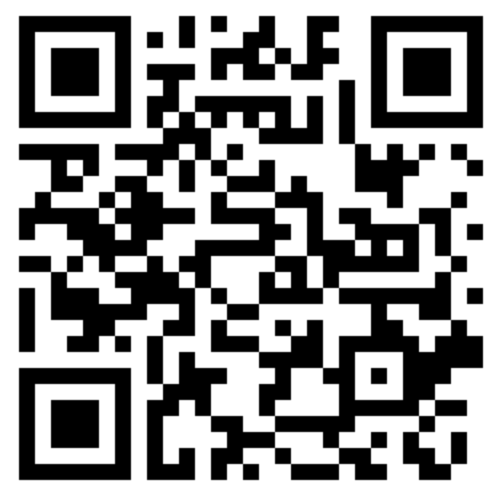

